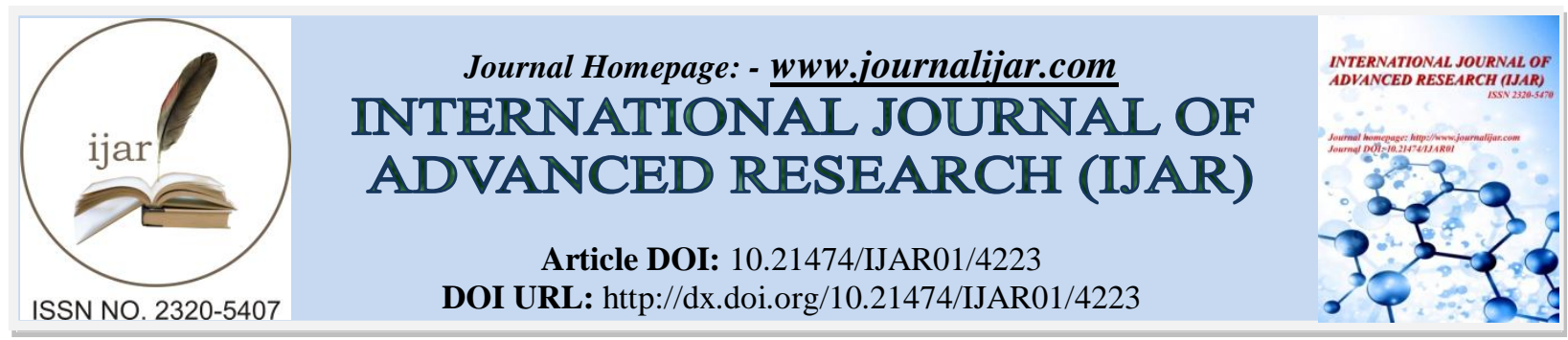

RESEARCH ARTICLE

\title{
ACCELERATED PARTIAL-BREAST IRRADIATION: A STATE OF THE ART STRATEGY
}

\author{
Ebtesam Hamoud ${ }^{1}$, Ismail Ghorbel ${ }^{1}$, Keyan Falfali $^{1}$, Attiya Bin Mohammad Al Zahrani ${ }^{2}$, Yousef Al Alawi ${ }^{2}$, \\ Sharif Qatarneh $^{3}$, Omar Alzahrani ${ }^{1}$ and Mostafa Abdelrahman'. \\ 1. PSOC-KSAFH- Radiation Oncology Service. \\ 2. KSAFH- Breast \& Endocrine surgery service. \\ 3. PSOC-KSAFH - Medical physics unit.
}

\section{Manuscript Info}

Manuscript History

Received: 18 March 2017

Final Accepted: 21 April 2017

Published: May 2017

Key words:-

Breast conservative surgery, partial breast

irradiation, whole breast irradiation, , cosmetic

results, Brachytherapy

\section{Abstract}

Breast-conserving therapy consists of wide local excision (WLE) followed by whole-breast irradiation (WBI).It is already widely accepted as an alternative to mastectomy. It is used for the treatment of patients with early-stage breast cancer. Accelerated partial-breast irradiation (APBI) is a new strategy. It is characterized by being shorter $\&$ an alternative radiation technique for a highly selected patients with favorable early-stage breast cancer. The objective of this review article is to analyze different modalities of APBI delivery and discuss the possible benefits and harms associated with this new platform.

Copy Right, IJAR, 2017,. All rights reserved.

\section{Introduction:-}

Breast cancer has the highest incidence among all cancers in female. In early-stage breast cancer (stage $\leq$ II), the use of breast-conserving therapy (BCT) is a well-established treatment option. It is comparable to total mastectomy with good results as far as rates of local-regional control and overall survival. It enables patients to maintain their breasts with an acceptable cosmetic results [1]. In the initial trials regarding BCT that were done in the 1970s and 1980s, the new strategy typically involved segmental mastectomy with level I \& II axillary lymph node dissection, followed by whole-breast irradiation (WBI). Radiation therapy (RT) is given with a dose of 45-50 Gy over the course of 5 weeks, with or without a boost to the tumor bed. WBI is a relatively well-tolerated treatment. This modality has resulted in good long-term cosmetic results, with low rates of treatment-associated morbidity. The Early Breast Cancer Trialists' Collaborative Group in their meta-analysis has demonstrated that the addition of radiation therapy (RT) to breast-conserving surgery has improved not only local-regional control, but also long-term overall survival [2]. In accelerated partial breast irradiation (APBI) a limited volume of breast tissue is irradiated. This includes tumor bed, lumpectomy or wide local excision with safety margins. It is delivered over a short period of time with increasing the fraction dose. Changing the strategy from whole breast irradiation to a small target (only part of the breast) as in APBI needs full investigation \& scrutiny not only because of potential changes in local control but also for its possible impact on the overall survival .

\section{Aim of This Review:-}

Despite of the presence of advanced studies, the role, indication and the optimum APBI technique are still yet to be clearly identified. Therefore, in this review, we will try to find an answer for a number of controversial issues for better identification of the following: 
1. The suitable patient for ABPI

2. The target volume in ABPI

3. The best ABPI technique taking into consideration the advantage and disadvantage of each one.

\section{Discussion:-}

The Rationale behind APBI:-

Accelerated partial-breast irradiation (APBI) is a strategy in which only the area of the breast where the tumor was initially located is targeted with irradiation. The treatment is typically delivered over 1 to 15 days. In WBI it encompasses the whole breast parenchyma, chest wall musculature, ribs, and approximately $60 \%$ of level I and II lymph nodes. On the other hand APBI radiation is typically focused on a 1-2 cm margin of tissues surrounding the lumpectomy cavity (Figure 1).
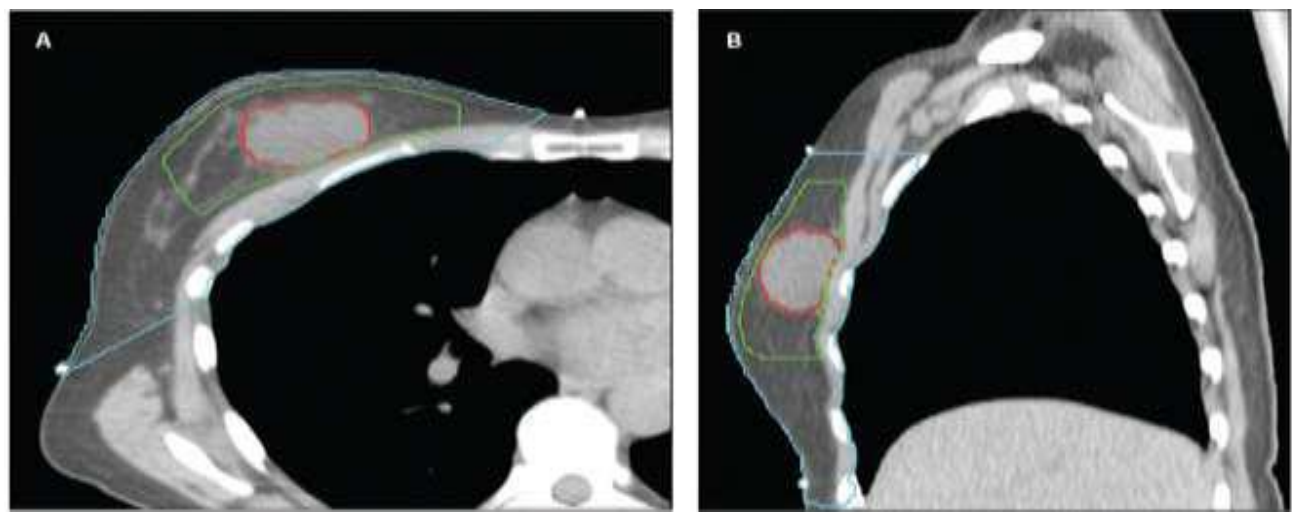

Figure 1:- Target Volume for External Beam APBI

Axial (A) and sagittal (B) images showing the target areas in breast radiation. The area outlined in blue is typically encompassed within a WBI treatment filed. The red line outlines the lumpectomy cavity. The green line outlines the area that would be targeted with external beam-based ABPI

The rationale for partial-breast irradiation (PBI) arised from the observation that the majority of breast cancer recurrences occur in close proximity to the lumpectomy cavity. The evidence was retrieved from several clinical trials. Data from three trials comparing treatment with lumpectomy alone \& lumpectomy followed by WBI reported that the incidence of distant treatment failures were similar in patients who received WBI as in those who did not $[1,3,4]$. These finding indicate that the main local benefit of WBI is in the area of the tumor bed. PBI would reduce dose to uninvolved breast tissue, the lungs, the ribs, the chest wall musculature, and the heart. This will definitely reduce the risk of late complications [5]. In addition, APBI can resolve various problems that are facing breast cancer patient as: access, cost and logistical issues; lack of social support structure and poor ambulatory status of the patient $[6,7,8,9]$. When compared with a 5- 6 weeks WBI treatment, it has been argued that the shorter course of APBI will improve patient satisfaction and overall quality of life. Furthermore, APBI will potentially minimize the psychological and physical strains associated with radiation treatment $[10,11]$. Another advantage is encountered in patients who live far from a radiation oncology facility, particularly for those who suffer from multiple medical comorbidities. The other important point is that a shorter treatment might improve compliance with completing the prescribed course of radiation therefore reducing the choice of mastectomy over BCT $[12,13,14,15,16]$. Several studies have demonstrated that the microscopic extension of malignancy, and the ipsilateral breast tumor recurrence is unlikely to be beyond $1 \mathrm{~cm}$ of the tumor $[17,18,19,20,21]$. However, other studies showed that there were tumor foci beyond $2 \mathrm{~cm}$ from tumor bed, so they encourage WBI instead of PBI [22]. ABPI was compared with WBI, ABPI improved the rate of cosmetic results in the breast and the quality of life without increasing local recurrence rate $[7,23,24,25,26]$.ABPI decreases the dose to normal tissue and the surrounding organ at risk (as lung, heart) [18, 27, 28,29].

\section{APBI: Techniques and Clinical Outcomes:-}

Multiple distinct treatment modalities have been used to deliver APBI, including brachytherapy, intra-operative techniques (x-rays, electrons), and external irradiation with photons or less likely by protons. Each modality offers advantages and disadvantages, depending on patient anatomy and preference, as well as the resources available at 
the radiation oncology facility. Ideally, each patient is assessed for the technique that will match with her different clinical, radiological \& pathological parameters (Figure 2).

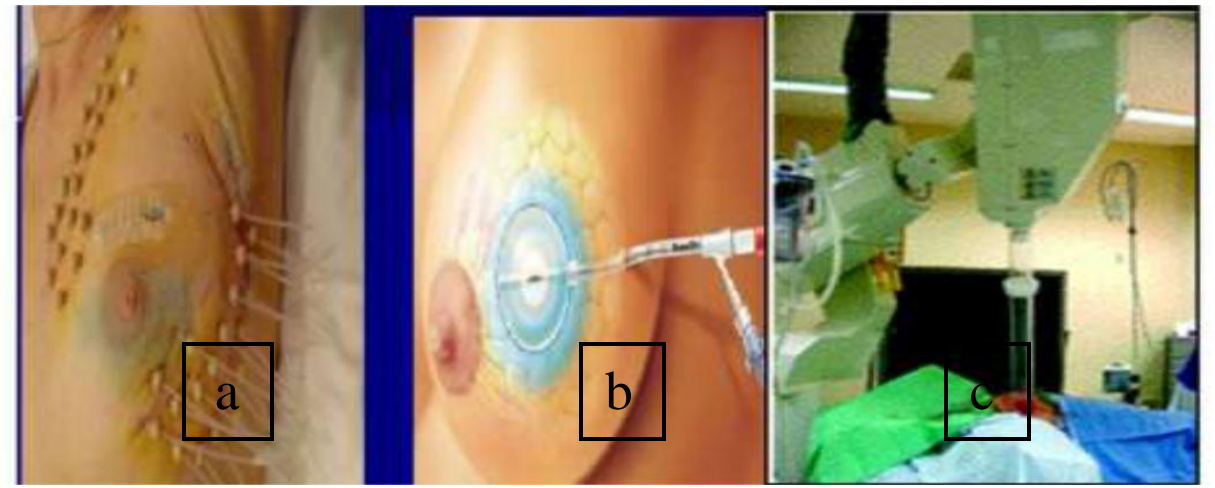

Figure 2:- Various Techniques of ABPI.

Multi-catheter interstitial brachytherapy. (b) single intra-cavitary brachytherapy catheters. (c) intra-operative radiotherapy

\section{Multicatheter interstitial brachytherapy (MIB):-}

MIB is a brachytherapy technique that was used for APBI [24,30,31]. Initially, it was used as a boost radiation postwhole breast RT. This is an after loading technique. Catheters are placed through the breast tissues (surrounding the lumpectomy) [32,33]. Procedure is done under loco-regional anesthesia. 1 to $1.5 \mathrm{~cm}$ intervals will be allowed between the catheters to avoid hot and cold spots and to ensure adequate coverage of the lumpectomy cavity \& a safety margins. The number of catheters is between $14-20$ catheters (determined by the size and shape of the target volume). In MIB either low dose rate (LDR) or high dose rate (HDR) brachytherapy are used. There are various schedules for dose prescriptions, for example: total dose $34 \mathrm{GY}$ ( $3.4 \mathrm{~Gy} / \mathrm{fr}, 2 \mathrm{fr}$ at day, $10 \mathrm{fr}$ ); $32 \mathrm{~Gy}$ (4 Gy/fr, $2 \mathrm{fr}$ at day, $8 \mathrm{fr}$ ). Twice daily with minimum of 6 hours between fractions. The disadvantages include the need for a high level of experience for catheter insertion using a free-hand technique [34]; CT and other image guidance are important to prepare virtual planning (Figure 3).
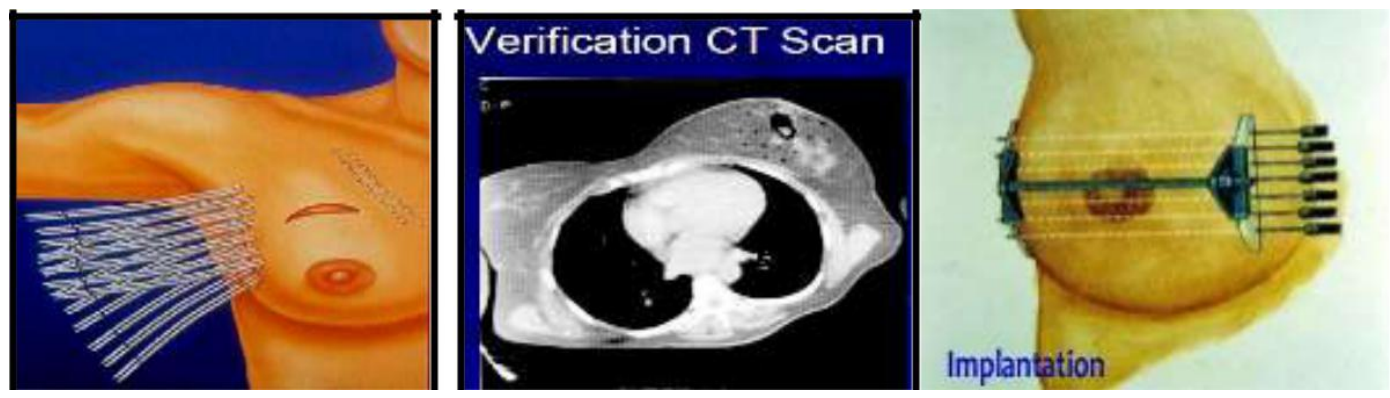

Figure 3:- Multicatheter interstitial brachytherapy (MIB).

MIB is the APBI technique with the longest follow-up and the most mature data to support its use. This technique allows for a highly conformal treatment, with near complete sparing of surrounding normal tissues due to the rapid fall off of the dose. The Radiation Therapy Oncology Group (RTOG) conducted a phase II, multi -institutional study, RTOG 95-17, which included 99 patients with early-stage breast cancer treated with APBI delivered via low or high dose rate brachy-therapy. In this study, the 10-year rate of ipsilateral breast tumor recurrence (IBTR) was $6.2 \%$, and half the recurrences were reported outside the area of the treatment field [35].In another trial performed at the National Institute of Oncology in Hungary 258 women were randomly assigned to APBI or WBI, with APBI delivered either via MIB high dose rate (HDR) brachytherapy or external electron beam irradiation. The rates of recurrence at 10 years were not significantly different in the two arms (5.9\% for APBI vs 5.1\% for WBI). In patients treated with APBI a higher rates of good to excellent cosmesis was noted $(81 \%$ vs $63 \%, P=.009)[36]$. MIB was considered by many authors as an invasive procedure and is associated with the risk of infection and scarring. In a prospective data published on interstitial brachytherapy used to deliver APBI, the rates of infection range from $0 \%$ - 
$11 \%$, with the majority of trials reporting rates < 5\%.[19-22]. To be mentioned MIB requires a high degree of expertise on the part of both the physician and the medical physics staff, this may explain the reasons why it is not that popular.

\section{Single-entry intracavitary brachytherapy:- catheters:-A-MammoSite Ballon (MSB):-}

As a result of the growing clinical interest in APBI and the need for a more easily implemented and less sophisticated techniques, intra- cavitary, single-entry brachytherapy catheters emerged as a new modality to deliver APBI using brachytherapy. This new technology is easy to be used by both the primary physicians and the physicists. It is also less traumatic for the patients. A catheter is inserted through a puncture site in the breast and positioned within the lumpectomy cavity, typically under ultrasound guidance after surgery has been completed. At the completion of treatment, the catheter is removed with or without local anesthetic in the office. Unlike with MIB, early, single-lumen versions of the catheters used in single-entry brachytherapy were restricted to patients with specific geometric characteristics, (ie, non-superficial surgical cavities). More recently multiple-lumen devices were introduced to allow greater flexibility in treatment planning. This technology has the advantages of better coverage of the target tissue at risk with minimal dose delivery to the nearby rib and skin.[37]. The US Food and Drug Administration (FDA) has approved the original single-lumen MammoSite catheter in 2002.Its use has increased dramatically in many cancer centers worldwide. It was estimated that the use of brachytherapy as a component of oncologic care has increased in incidence from < 1\% of cases in 2001 to $10 \%$ of cases by 2006 [38]. It has silicon balloon connected to double lumen catheter. MBS uses Ir-192 ( radio- active) source. CTV formed by tumor bed plus margin $1 \mathrm{~cm}$. Balloon-to-skin distance should be $>5 \mathrm{~mm}$ (better $>7 \mathrm{~mm}$ ). Prescription point is $1 \mathrm{~cm}$ from the balloon surface. In general, total dose is 34 Gy over10 fractions , so 3.4 Gy per fraction, twice daily (minimum of 6 hours between fractions) over 1week. MBS has Good /excellent cosmesis with low risk of recurrence [39,40,41,42]. MBS has various disadvantages including: its central source channel does not allow for shaping radiation iso-dose curves in the direction perpendicular to the central channel; it is an invasive device and its applicator can be placed into the lumpectomy cavity at the time of surgery or in a separate procedure after surgery, using old or new incision; when applicator is inserted under ultrasound guidance, it needs good experience; it is not suitable technique for small breast or for tumors located in the upper-inner quadrant, due to needing of skin-cavity distances (Figure 4 $a, b, c)$.

\section{B-Hybrid Brachytherapy Devices as (SAVI):-}

SAVI consists of a central strut surrounding by 6,8 or 10 peripheral struts, the device is inserted in a collapsed form through a small incision; once placed, it is then expanded to fit the lumpectomy cavity[43,44,45].SAVI device is surgically implanted using ultrasound guidance with the patient under local anesthesia. A CT scan is performed immediately following the implant surgery, both for the verification of the proper deployment of the device and for treatment planning [45] ( Figure 4 d,e).

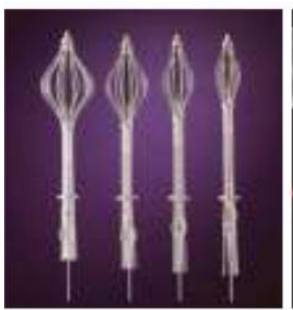

a

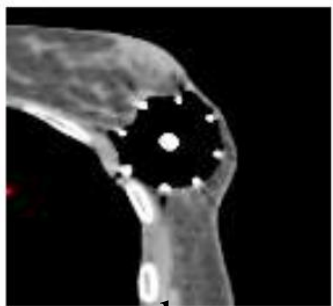

b

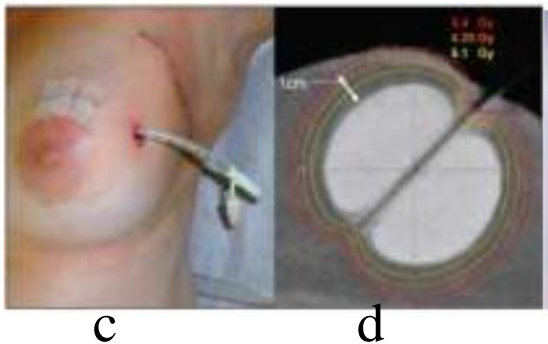

C

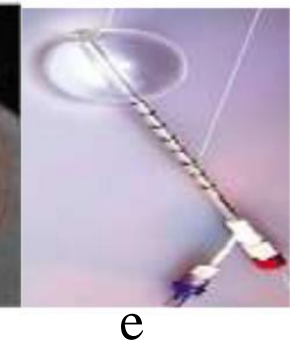

Figure 4 (a,b,c):- single entery intra-cavitary brachytherapy

Mammosite brachytherapy:- (a) ballon applicator, (b) External view, (c) sagittal views of balloon \& dosimetric target coverage.

Hybrid Brachytherapy Devices (SAVI ):- (d) different sizes of SAVI with peripheral struts expanded(e) axial view of SAVI.

The American Society of Breast Surgeons has prospectively followed a cohort of 1,440 women treated with the single-lumen MammoSite catheter. They reported a 5-year actuarial IBTR rate of 3.8\% [46]. Furthermore, 90.6\% of treated patients had good-excellent cosmesis, $13 \%$ developed symptomatic seromas, $9.5 \%$ developed an infection, 
and $2.3 \%$ developed fat necrosis. The results were comparable to those seen with MIB [47]. The toxicities of brachytherapy-based APBI were compared to those of WBI in population-based studies in a retrospective population-based cohort study of 92,735 women aged 67 or older with invasive breast cancer diagnosed between 2003 and 2007, treated with BCT, and followed through 2008 [48]. The study compared 6,952 women treated with brachytherapy vs 85,783 treated with WBI. The 5-year incidence of salvage mastectomy was slightly higher among women treated with brachytherapy (4.0\% vs $2.2 \%)$. Brachytherapy was also associated with a higher rate of infectious and noninfectious complications, including breast pain, fat necrosis, and rib fracture. A follow-up study by Presley et al reported on 29,648 patients aged 66 to 94 treated with BCT between 2008 and 2009 [49]. There was a significantly higher rate of wound and skin complications among the $15.8 \%$ of women who received brachytherapy compared to WBI (adjusted rate of $33.7 \%$ vs $16.8 \%, P<.001$ ), a rate that far exceeds anything published in the prospective literature. there was also significant geographic variability in the frequency of treatment delivery with brachytherapy nationally, a finding also demonstrated in a Surveillance done by Epidemiology,and End Results (SEER) database[50].

\section{External beam Radiation Therapy ( EBRT):-}

EBRT is a noninvasive technology, using standard linear accelerator. The machine is available in all advanced radiation oncology facilities. It is another acceptable way to deliver APBI [51]. EBRT includes various techniques as: 3D-conformal radiation therapy (3D-CRT)using multiple (4-5) fields[photons/electrons or Proton beams; intensity modulated radiation therapy (IMRT) [52]. CT simulation will be done for visualization of tumor bed seroma cavity, post-operative changes and surgical clips $[53,54,55,56]$. CTV is defined as tumor bed plus $1.5 \mathrm{~cm}$ margin[ limited by $5 \mathrm{~mm}$ from the skin and chest wall]. PTV is defined as CTV plus $1 \mathrm{~cm}$ margin [5mm to compensate set-up errors, $5 \mathrm{~mm}$ for respiratory movement].Presence of metal clips is recommended to helps us to define the target. Dose prescription differs from one center to another. In Italy a total dose $30 \mathrm{~Gy}$, delivered within one week (6 Gy per day is used). NSABP/ RTOG use a total dose of $38.5 \mathrm{~Gy}$, delivered within one week, $3.85 \mathrm{~Gy}$ per fr, 2 fr per day separated by at least 6 hours [57]. EBRT has important advantages including availability, noninvasive technique, no need for anesthesia, homogenous dose distribution, less complications with good-excellent cosmetic outcome [58,59] (Figure 5).

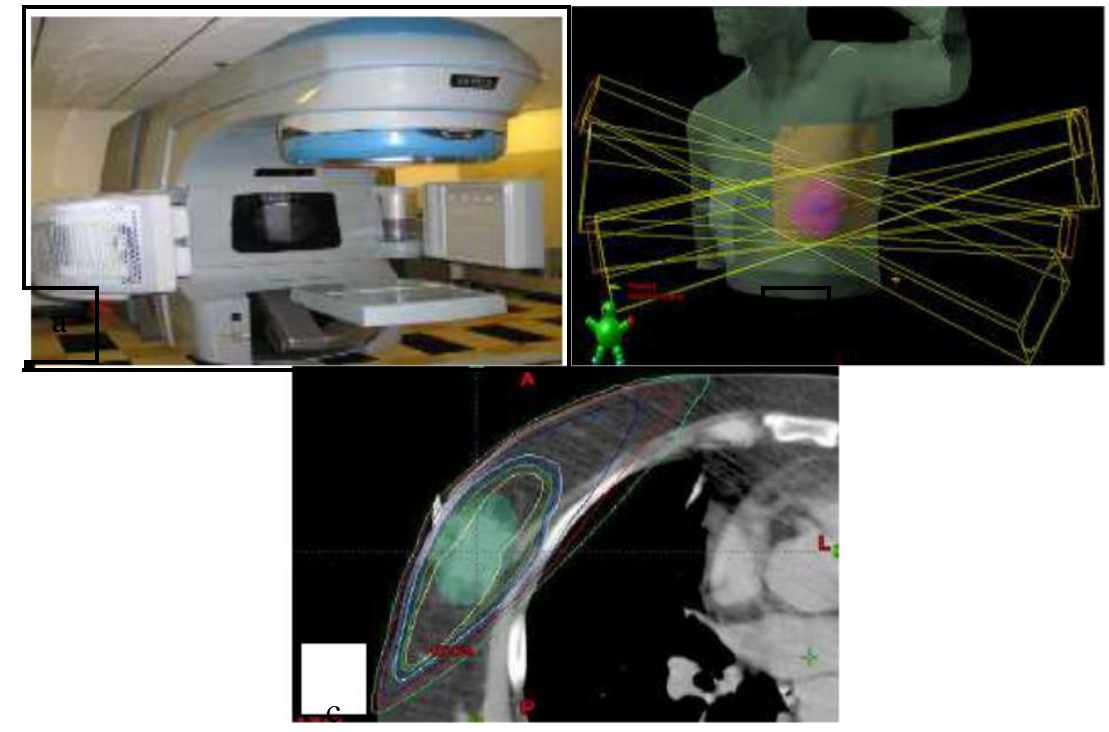

Figure 5:- (a) external beam technique, (b) various fields for left sided lesion,(c) target volume is well covered and OAR are well protected.

The RTOG published initial efficacy results from RTOG 03-19, a phase II, multi-institutional study using EBRT to deliver APBI to 58 patients with stage I-II breast cancer, tumors less than $3 \mathrm{~cm}$ in size and three or fewer involved lymph nodes, with negative margins following wide local excision (WLE) [60]. The authors reported a 4 years IBTR rate of $6 \%$, with two-thirds of these recurrences within the treatment field; $30 \%$ of patients developed grade 1 2 pain, and 4\% (2 patients) developed grade 3 skin toxicities. The Canadian cooperative group presented its large 
prospective trial at the annual meeting of the American Society of Radiation Oncology (ASTRO) in 2012 [61]. This trial randomly assigned 2,135 women aged $\geq 40$ years of age with early-stage breast cancer following BCT to either WBI or external beam, 3-dimensional conformal APBI. Cosmesis was assessed by the patient, physician, and a nurse, the results at 3 years following completion of treatment was worse in the group treated with APBI (ie, by nursing assessment, poor-fair cosmesis in $32 \%$ of patients treated with APBI vs $19 \%$ of patients treated with WBI, $P$ $<.0001)$. Grade 1-2 late radiation toxicities were also worse in the group treated with APBI.

\section{External beam Radiotherapy using protons:-}

Protons offer another external modality for the delivery of EBRT. It is noninvasive \& provides a sharper dose falloff than photon- and electron-based external beam irradiation. The delivery of proton treatment is available at approximately a dozen sites internationally. Initial dosimetric analyses comparing protons to photon-based APBI demonstrated that the former provided comparable coverage of the target tissue at risk while decreasing the radiation dose delivered to the non target breast, lung, and heart [62]. Unfortunately, the initial clinical publication from Massachusetts General Hospital reported on 20 patients, revealed a relatively high rate of toxicities (22\% of patients with moderate-to-severe moist desquamation at 6 to 8 weeks, 3 patients with telangiectasias, and 1 rib fracture, with a median follow-up of 12 months). In spite of this, 95\% of patients reported satisfaction with their treatment [63]. In another phase II study of 50 patients treated with APBI using protons, only 3 patients had late grade 1 telangiectasias, and acute toxicities were grade 1-2 in half of the patients[64].The use of proton therapy is progressively increasing worldwide and new centers will be operational in the near future.

\section{Intraoperative radiotherapy (IORT):-}

IORT means having a single fraction of RT, during the surgery, directly to the tumor bed in a single fraction [65,66]. The chief advantage of IORT is the delivery of radiation precisely to the operative bed at the time of surgery, without any prolonged treatment or additional invasive procedures. However, this treatment is delivered without image guidance, and concerns have been raised that radio-biologic assumptions regarding dose escalation break down at such high doses per fraction [67]. IORT has an important disadvantage, that the margin status is not known at the time of surgery. Therefore, it may require subsequent retreatment with additional radiation after the release of the final pathological findings. In IORT the PTV corresponds to CTV and consists of surgical bed (identified visually) plus radial margin at least $1-2 \mathrm{~cm}(\geq 1-2 \mathrm{~cm})$ to sterilize the anatomical areas next to the area surgically removed. IORT system is composed of miniature X-ray source, where electrons are accelerated to desired energy level within it; probe of [10 $\mathrm{cm}$ length plus $3.2 \mathrm{~mm}$ diameter]where the electrons/photons focused down the probe to strike the target inside the body; spherical applicators with various diameters ranging from $1.5-5 \mathrm{~cm}$ [68], are available to match the size of the surgical cavity [69]. The applicator will be fixed to the end of the source and placed in the excision cavity to obtain a homogeneous dose distribution on the surface of the applicator and consequently on the surface of the tumor cavity. When mounted onto the Intra-beam unit, each spherical applicator conforms the breast tissue around the radiation source to permit delivery of a uniform field of radiation to a prescribed tissue depth. Choosing adequate applicator and energy of the electron beam are very important to ensure adequate coverage of the target volume. The X-ray source generates mega-voltage (3-12) electrons or kilo-voltage photons. Using low-energy photons (30-50 KV) leads to a steep dose fall-off in soft tissue, therefore, no special shielding is required in the room[70]. The prescribed dose is a single dose of $21 \mathrm{~Gy}$ (biologically equivalent 58-60 Gy in standard fractionation). Dosimetry varies by tip and size of the applicator (for example, sphere applicator $3.5 \mathrm{~cm}$ delivers $20 \mathrm{~Gy}$ at $1 \mathrm{~mm} ; 5 \mathrm{~Gy}$ at $1 \mathrm{~cm} ; 1 \mathrm{~Gy}$ at $2.7 \mathrm{~cm}$ from its surface in about 20 minutes)[69] (Figure 6).
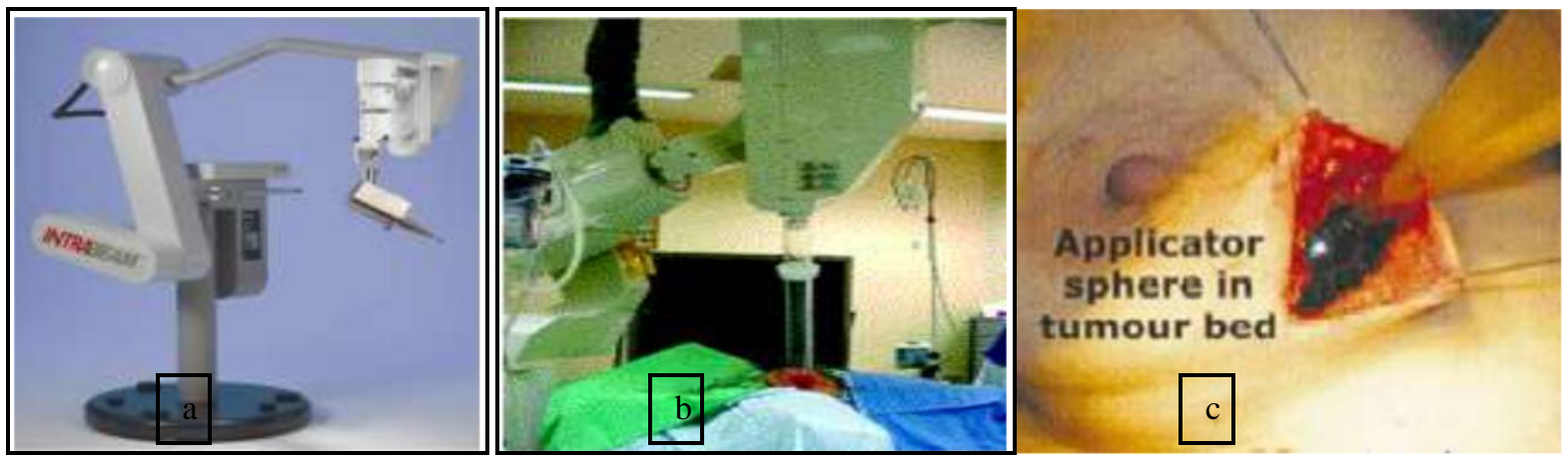

Figure 6:- Intra-operative RT(IORT). (a) X-ray source, (b) the probe, (c) applicator sphere in tumour bed. 
Advantages of IORT[68,71]: reduce the chance of tumor-cells proliferation before the end of operation; RT is delivered under direct visualization. At the time of surgery, and directly to surgical margins; increase Oxygen effect (the tissues under surgical intervention have rich vasculature and aerobic metabolism which makes them more sensitive to the RT); reduce skin and subcutaneous toxicity (due to the possibility of displace them during the IORT ); excellent cosmesis with low risk of recurrence [ 72] and allows to give RT without delaying other treatment as chemo-therapy or hormonal therapy. Disadvantages of IORT includes the need to mobile IORT devices. It was started in 1998 but until now, it is not widespread due to its' high cost; increase duration time of the operation due to IORT time that lasts for 20-45 minutes, depending on (dose, applicator, lumpectomy cavity size); final pathology reports are released days post-surgery, this issue is one of the major criticisms of this technique. So recently, a novel handheld probe has been developed for intra-operative detection of positive margins to reduce re-excision rate and improve IORT technique [73]. The Targeted IORT (TARGIT-A), a randomized controlled has published data on 2,232 patients in whom intra-operative kilovotage $(\mathrm{kV}) \mathrm{x}$-rays were used to target $1 \mathrm{~cm}$ away from the lumpectomy cavity, compared with WBI with or without a boost [65]. Kilovoltage x-rays are considered to be more radiobiologically effective than the megavoltage x-rays used in traditional external beam RT; different forms of radiotherapy (RT) have invitro differential degrees of effect on such biologic endpoints as tumor cell kill or even damage to normal tissues, such as ribs [74] However, debate remains as to whether the dose prescribed is sufficient to provide tumor eradication ie equivalent to what is provided by WBI or other forms of APBI.[67]. At 4 years, the rate of in-breast recurrence in TARGIT-A clinical trial was equal in the two arms (1\%) each. Investigators in Milan presented their findings from the Electron Intra-operative Trial (ELIOT), in which 1,305 patients were randomly assigned to receive either WBI with a boost or intra-operative treatment with electrons[66]. At 5 years, $3 \%$ of patients receiving APBI had a failure in the same quadrant as the primary tumor, compared with $1 \%$ of those treated with WBI. Breast failure elsewhere was $2 \%$ with APBI and $0 \%$ with WBI. Regarding toxicities in the two arms, the patients treated with APBI did better than those treated with WBI, according to data presented at the 2012 World Congress of Brachytherapy[66].

\section{APBI vs WBI:-}

WBI treats the breast as if every part were equally at risk for recurrence. A RT dose appropriate for the presumed microscopic disease control is prescribed. Hot spots are generally considered undesirable due to toxicity concerns. During treatment planning, efforts are made to keep the radiation dose throughout the breast as homogeneous as possible with dose distribution within the range of $\pm 10 \%$ or better. The addition of a boost improves local control by approximately $40 \%$, although at the cost of tripling the incidence of fibrosis (with a 10-year rate of $4.4 \%$ with the boost vs1.6\% without boost. In the trial of the European Organization for Research and Treatment of Cancer [EORTC] 22881-10882 trial) [75]. Most boost targets are defined by a margin around the surgical cavity. The literature contains reports of margins ranging from 0 to $2.5 \mathrm{~cm}$. From the planning and treatment delivery standpoint, a photon boost to the surgical cavity $+2 \mathrm{~cm}$ can be virtually indistinguishable from external beam APBI. External beam approaches offers uniformal dose distribution within the irradiated volumes. However brachytherapy doses are not considered uniform. When using a balloon catheter, radiation doses at the cavity can be more than double those seen in external beam treatment, and the dose falls off continuously with distance (Figure 7).

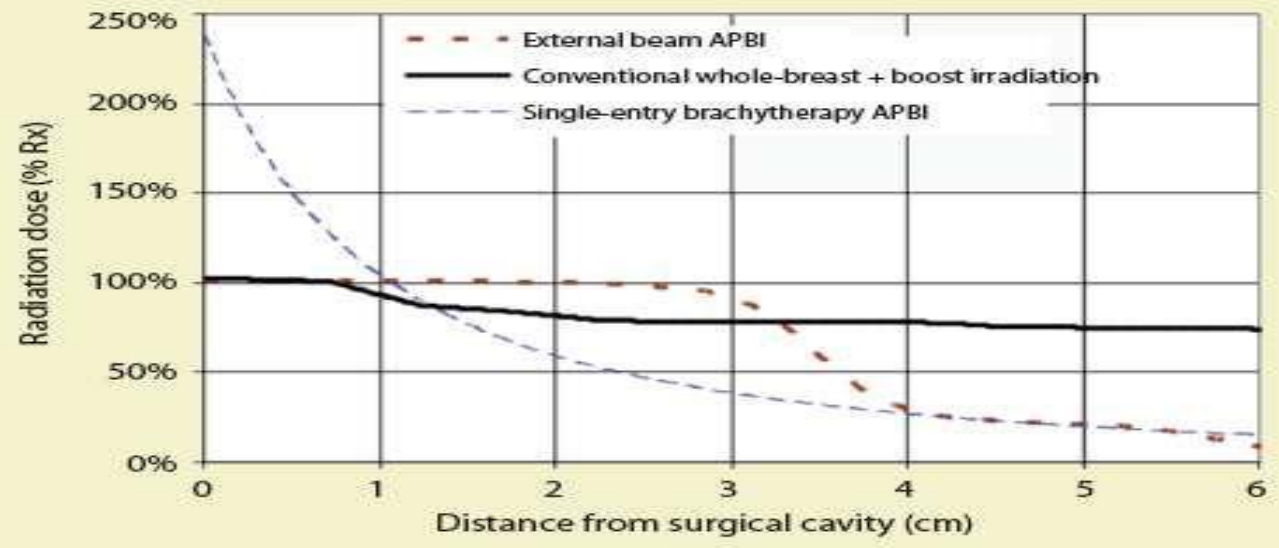

Figure 7:- Comparison of the Dose Distributions of the Whole- Breast Irradiation with a Boost, External APBI, and Single-entry Brachytherapy APBI. APBI=accelerated partial breast irradiation; $\mathrm{Rx}=$ prescribed dosage 
WBI treat the breast as being at one uniform risk level for recurrence or two uniform risk levels as in (WBI + boost, external beam ABPI), brachytherapy, especially single-entry, essentially treats risk as continuously decreasing with distance from the cavity. It would be useful to map the actual spatial dependence of local recurrence risk against the different dose profiles that is shown in (Figure 7). The result might well support a more adapted approach to breast radiotherapy than an all or none approach, WBI vs APBI dichotomy. Unfortunately, at this time, applicable pathological studies are scarce. Although - partial-breastl irradiation has been cited as the factor that permits -accelerated\| irradiation, radiobiological calculation shows that the doses commonly delivered by APBI are actually equivalent to those of WBI in terms of both expected local control and toxicity[76] Therefore, the - partiall and - accelerated $\|$ aspects of APBI can be viewed as separate rather than going hand-in-hand. Accelerated WBI, commonly delivered over 3 weeks, is becoming more and more widely adopted. On the other hand, it has been argued that partial-breast irradiation should be less accelerated. Given the dose equivalence, it has been unclear why APBI, which irradiates less of the breast, has been reported to have, at best, toxicity equivalent to WBI. It is the twice-daily treatment that allows common forms of APBI to be delivered in 1 week as opposed to multiple weeks, and it has been suggested that using a once-daily treatment might resolve this issue [77].

\section{Comparison of APBI Modalities:-}

External beam APBI treat larger tissue than the technique using brachytherapy [78]. The target volume in different APBI modalities typically involve different radiation dose prescriptions. Radio-biologic calculations have been made in an attempt to define the degree to which the distinct methods of delivering APBI are equivalent to WBI; however, most of these have been done post hoc and have not been based on any endpoints of local control [76,79]. One study demonstrated that differences in dose homogeneity suggest that external beam dose prescriptions should be slightly higher than MIB brachytherapy prescriptions (as is the usual practice) to be equally effective[80]. There is debates about the equivalency of the doses prescribed with intra-operative x-ray or electron-based radiation compared with the other modalities of APBI [67]. Even when comparing relatively similar brachy-therapy techniques for delivering APBI, there remains uncertainty regarding the appropriate dosimetric criteria needed to minimize the risk of toxicities such as fat necrosis. In the initial clinical experiences with interstitial catheter-based brachy-therapy, symptomatic fat necrosis reported range from $2 \%$ to $21 \%$ of cases[81, 82] .The current guidelines in the National Surgical Adjuvant Breast and Bowel Project (NSABP) B-39/RTOG 0413 protocol regarding the volume of higher doses of radiation permissible on study are based on earlier dosimetric analyses from Tufts University and Virginia Commonwealth University that correlated larger volumes of high doses of radiation in the breast with the development of fat necrosis [83]. It is difficult to know how to translate these dosimetric constraints from one brachytherapy modality to another, which is important given that balloon and single-entry catheter based brachytherapy catheters yield significantly different dose distributions. Additionally, tumor proximity to such structures as the ribs, chest wall musculature, and skin may result in a different outcome with APBI, given the relatively steep dose gradient in the area targeted (Figure 8) (Table 1).
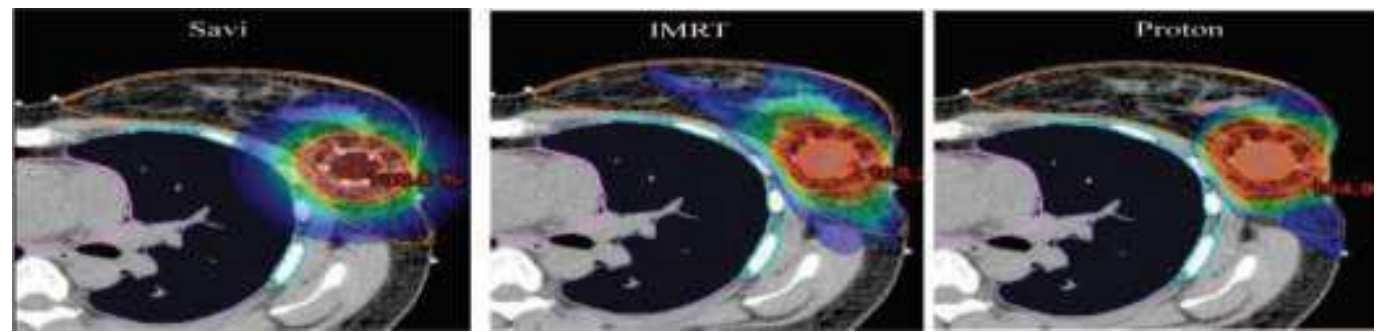

Figure 8:- Comparative APBI treatment planning using: BT( SAVI) device, IMRT intensity-modulated radiation therapy and PBT( proton beam therapy) 
Table 1:- Comparison of APBI modalities.

ER: External Beam. IORT: Intra-Oprative RadioTherapy. MIB: Multi-catheter Interstitial Brachythyrapy. Hybrid based brachytherapy.

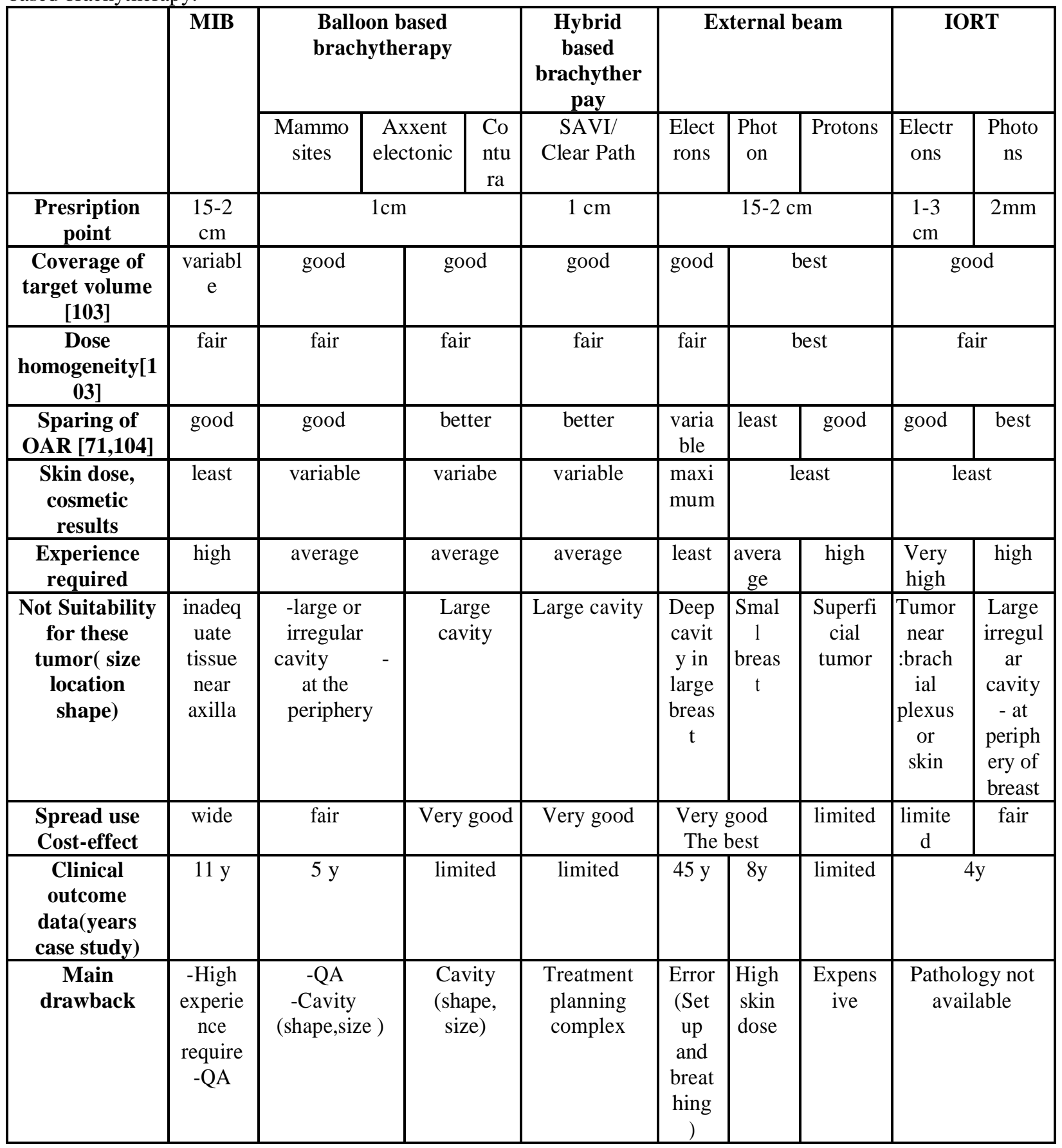

\section{Quality of Life Benefits:-}

In general, patients who receive APBI express deep gratitude when offered the option of a more condensed treatment. Surprisingly, there have been limited published data obtained from surveying women in order to better understand their feelings regarding the convenience of finishing radiation treatment within 1 week with twice-daily treatments compared with daily treatment over 3 to 6 weeks [84]; therefore, it remains difficult to quantify this benefit, which results in physicians relying on anecdotal stories of individual patients they have treated. One of the original rationales behind APBI was that it would enable more women to have access to BCT for whom it would have been too difficult to undergo a more prolonged course of WBI and who might otherwise have opted to 
pursue mastectomy for this reason alone. To our knowledge, no study has yet documented the trends in utilization of BCT vs mastectomy since APBI has become more broadly used, and we would welcome research toward this end. The population-based studies that have been published have found that brachytherapy-based APBI has been most prevalent in renowned tertiary care hospitals and advanced cancer centers [85].This difference in treatment delivery may be due to both patient preference and available resources, as HDR brachytherapy and the expert team are not available in centers in rural areas. So far, there has been no published documentation on the trends in usage of external beam - based APBI in these center.

\section{The Costs of APBI:-}

The overall clinical cost of APBI, to both patients and society, has not been fully quantified. A shorter course of external beam APBI clearly costs less than a protracted course of external beam WBI in terms of the amount billed to the patient, the number of healthcare resources used, and the financial cost to the patient in terms of time away from work and family $[86,87,88]$. However, since the inception of single-entry brachytherapy catheters, patterns of reimbursement have changed significantly. With this technique, typically there is a financial charge for the catheter and the placement of the catheter by the surgeon. In addition, this treatment technique is significantly more timeintensive to the physician and medical physicist involved in the case, and reimbursement has varied over time, with the amount paid increasing in accordance with the number of lumens treated, a reflection of the greater complexity of the case. A few publications analyzing the cost of APBI compared with WBI have resulted in mixed findings[87,88,89]. In general, these studies have shown that external beam - based APBI is significantly less expensive than standard fractionation WBI over 5 to 6 weeks. However, the comparison of brachytherapy -based APBI to WBI with boost is more complicated and the costs of these two approaches appear generally comparable; however, such things as intensity -modulated radiotherapy (IMRT) treatment plans and the brachytherapy catheter itself add additional costs. Proton-based treatment in general has been found to be more costly than other more traditional forms of radiation therapy, although the cost of proton-based APBI and that of traditional WBI have not yet been directly compared .Most APBI regimens require twice-daily treatment, with a minimum 6-hour time interval between treatments, a regime for which many patients require time off from work. However, these patients typically finish RT within 1 week instead of the traditional 6 weeks of standard WBI, which means a less prolonged interruption of normal work and home activities. This difference might be minimized as hypo-fractionated WBI continues to increase in use, allowing treatment of the whole breast in 3 to 4 weeks. Cost benefit analysis have demonstrated that certain modalities for delivering APBI might also decrease the overall financial cost of treatment compared with WBI [86, 87, 88.89]. Brachytherapy based APBI is more labor-intensive from the perspective of the breast surgeon, radiation oncologist, and medical physicist. This treatment requires close communication and synchronization of scheduling between the breast surgeon and the radiation oncologist, this can be challenging in a busy clinical practice. In addition, the Nuclear Regulatory Committee requires the attendance of both a radiation oncologist and a medical physicist at the delivery of each fraction of radiation for brachytherapy and intraoperative treatment, in addition to daily quality assurance by the medical physicist. It is estimated that this adds at least 10 extra hours work per patient compared with external beam-based treatment.

\section{Guidelines (Selection Criteria of APBI):-}

At the beginning of 2007, four separate oncologic societies have published guidelines to assist physicians in selecting patients for APBI offered off protocol (Table 2). ASTRO organized a task force that published the most detailed set of guidelines regarding suitability to receive APBI off protocol. This group recommended that women be classified as - suitablell for APBI treatment if they are age 60 or older and have invasive ductal carcinoma (or other favorable histology) $\leq 2 \mathrm{~cm}$; estrogen receptor positive; unicentric and unifocal; lymph node negative; with negative margins $(\geq 2 \mathrm{~mm}$ ); and with no extensive intraductal component (EIC), lymphovascular space invasion (LVSI), or neo-adjuvant therapy [90]. The Groupe Europen de Curiethrapie and European Society for Therapeutic Radiology and Oncology (GEC-ESTRO), the American Society of Breast Surgeons, and the American Brachytherapy Society have all published their own sets of guidelines [91, 92, 93]. These four sets of guidelines were based on older published studies and the inclusion criteria used there in coupled with the judgment of experienced. Recent guide lines were done by various oncologic societies as NCCN,AIRO,ASTRO and GECESTRO as illustrated in the (Table 3) . 
Table 2:- Published Consensus Statement Criteria for the Delivery of APBI Off Protocol.

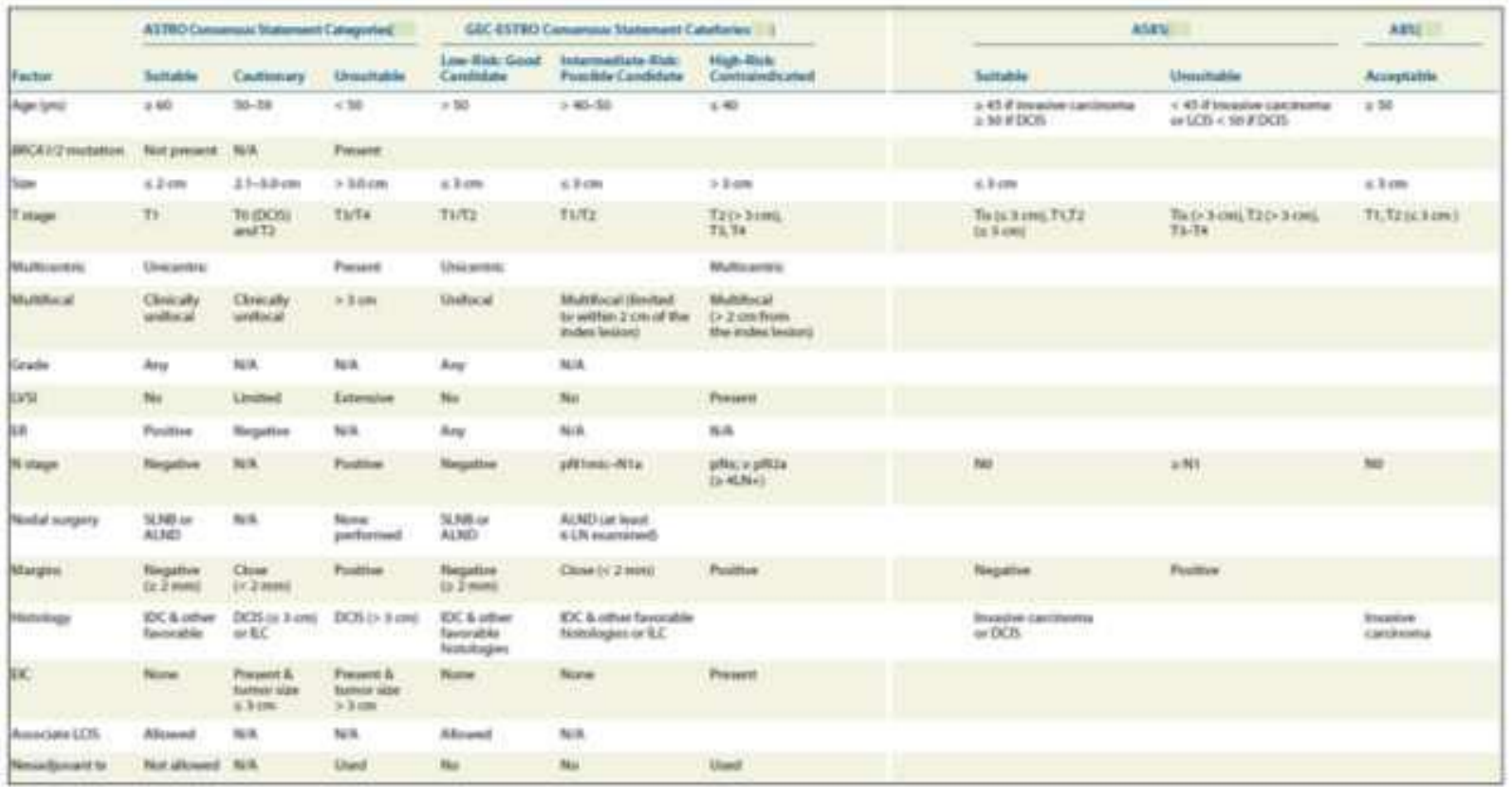

ABS: American Brachytherapy Society, ALND: axillary lymph node dissection, ASBS:American Society of Breast Suregons, ASTRO:American Society of Radiation Oncology,DIC:ductal carcinoma in situ, EIC: extensive intraductal component, ER:estrogen receptor, GEC-ESTRO: group Europen de Curietherapie and European Society for Therapeutic Radiology and Oncology, IDC:invasive ductal carcinoma, ILC:invasive lobular carcinoma, LCIS:lobular carcinoma in situ, LN:lymph node, LVSI:lymphovascular space invasion, N/A:not available, RT:radiotherapy, SLNB:sentinel lymph node biopsy, TX:therapy

Table 3:- illustration of APBI Guide Lines by different authorisies

\begin{tabular}{|c|c|c|c|c|}
\hline Factors & NCCN [94] & AIRO [95 ] & ASTRO[96] & $\begin{array}{r}\text { GEC-ESTRO } \\
{[97]}\end{array}$ \\
\hline Age & $\geq 60 y$ & $>60$ & $>60 \mathrm{yrs}$ & $>50 \mathrm{yrs}$ \\
\hline $\begin{array}{r}\text { Stage } \\
\begin{array}{r}\mathrm{pT}, \text { tumor size } \\
\mathrm{pN}\end{array}\end{array}$ & $\begin{array}{c}\mathrm{T} 1 \\
\mathrm{pN} 0\end{array}$ & $\begin{array}{l}\text { T1, T } \leq 2 \mathrm{~cm} \\
\text { pN0 (i-, i +) }\end{array}$ & $\begin{array}{c}\mathrm{T} 1, \mathrm{~T} \leq 2 \mathrm{~cm} \\
\mathrm{pN} 0\end{array}$ & $\begin{array}{c}\mathrm{T} 1-2, \mathrm{~T} \leq 3 \mathrm{~cm} \\
\mathrm{pN} 0\end{array}$ \\
\hline $\begin{array}{r}\text { Multicentr } \\
\text { Multifocale }\end{array}$ & $\begin{array}{l}\text {-Unifentric } \\
\text {-Unifocal }\end{array}$ & $\begin{array}{c}\text {-Unicentric } \\
\text {-Unifocale (microscopic } \\
\text { multifocality with total } \\
\text { dimension } \leq 2 \mathrm{~cm} \text { is } \\
\text { allowed) }\end{array}$ & $\begin{array}{c}\text { - Unicentric } \\
\text { - Unifocal } \\
\text { (total size }<2 \mathrm{~cm} \text { is } \\
\text { allowed) }\end{array}$ & $\begin{array}{l}\text { - Unicentric } \\
\text { - Unifocal }\end{array}$ \\
\hline Histopathology & $\begin{array}{c}\text { Invasive } \\
\text { ductal ca /f } \\
\text { avorevole } \\
\text { ducal subtyp }\end{array}$ & $\begin{array}{l}\text { Invasive ductal } \\
\text { carcinoma /other } \\
\text { favorable histologic } \\
\text { types, (as mucinous, } \\
\text { tubular ,colloid) }\end{array}$ & Invasive ductal & Invasive ductal \\
\hline Grade & -- & any & Any & Any \\
\hline Margins & Negative & $\geq 2 \mathrm{~mm}$ & $\begin{array}{l}\text { Negative } \\
(\geq 2 \mathrm{~mm})\end{array}$ & $\begin{array}{l}\text { Negative } \\
((\geq 2 \mathrm{~mm})\end{array}$ \\
\hline LVI & -- & Negative & No & Not allowed \\
\hline $\begin{array}{r}\text { Associated LCIS } \\
\text { Pure DCIS }\end{array}$ & $\begin{array}{c}\text { Absence } \\
--\end{array}$ & $\begin{array}{c}\text { Absence of extended in- } \\
\text { situ component }(\geq \\
25 \%)\end{array}$ & $\begin{array}{c}\text {-Allowed } \\
\text { - Not allowed }\end{array}$ & $\begin{array}{l}\text {-Allowed } \\
\text { - Not allowed }\end{array}$ \\
\hline EIC & Negative & -- & Not allowed & Not allowed \\
\hline
\end{tabular}




\begin{tabular}{|r|c|c|c|c|}
\hline BRCA 1/2 mutation & Negative & Negatve & Not present & -- \\
\hline ER & ER+ & ER+ & Positive & Any \\
\hline Neo-adjuvant & No & No & Not allowed & Not allowed \\
\hline chemotherapy & & & & \\
\hline
\end{tabular}

NCCN: National Comprehensive Cancer Network. AIRO: Associazione Italiana Radioterapia Oncologica.ASTRO: American Society for Radiation Oncology.GEC : Gynaecological working group. ESTRO: European Society for RT and Oncology. APBI: accelerated partial breast irradiation, IDC: invasive intraductal component ,LVI:lympho-vascular invasion, ER:esterogen receptor status, ** based on sentinel node biopsy or axillary lymph node dissection.

Closed Randomized Trials comparing APBI \&WBI reported that the guidelines are related to general risk factors for the recurrence of breast cancer in the setting of BCT. To our knowledge, none of the criteria listed are known to directly correlate with a patient's risk of having a higher rate of recurrence if she receives radiation to the whole breast vs. to the lumpectomy cavity only. We believe that additional pathologic data with mapping of the extent of disease could help in better determination of the suitability to receive APBI. Therefore the impact of the consensus statements on patient selection for treatment with APBI remains uncertain. Some experts have raised the concern that the phrasing chosen in these publications may be misleading [98.99].Given that these four organizations have not been able to agree on the most important factors in patient selection for the delivery of APBI, the individual medical practitioner will continue to have difficulties to make a decision about how to apply the guidelines reported in the literature to a given patient's clinical scenario. However, we still believe that the published guide-lines do offer some direction to clinicians and serve as a useful reference for decision making.

\section{APBI: The Future:-}

The data for four randomized trials $[36,61,65,66]$ comparing WBI and APBI were partially presented (Table 4); so far the results regarding toxicity and efficacy have been mixed.

Table 4:- Closed Randomized Trial Comparing APBI and WBI.

\begin{tabular}{|c|c|c|c|c|c|c|c|c|c|c|}
\hline Trial Name & location & $\begin{array}{l}\text { Patient } \\
\text { Inclusion } \\
\text { Criteria }\end{array}$ & Surgery & $\begin{array}{l}\text { Control Arm: } \\
\text { WBI }\end{array}$ & $\begin{array}{l}\text { Test Arm: } \\
\text { Apgi }\end{array}$ & $\begin{array}{l}\text { Median } \\
\text { follow-up }\end{array}$ & Accrual & Local Failure & Notable Features & Toxicity \\
\hline $\begin{array}{l}\text { National Institute } \\
\text { of Oncology| }\end{array}$ & Hungary & $\begin{array}{l}\text { IDC, pTI, No, } \\
\text { pNa-1mic, } \\
\text { grades 2, uni- } \\
\text { focal no EC; } \\
\text { after year } 2001 \\
>40 \text { yrs }\end{array}$ & $\begin{array}{l}\text { Wide excision } \\
\text { negative margins }\end{array}$ & $\begin{array}{l}42-50 G y \\
121-25 t x\end{array}$ & $\begin{array}{l}\text { MBHDR } \\
364 \text { Gy/7fx } \\
\text { or electrons } \\
42-50 G y \\
121-256 x\end{array}$ & $10 \mathrm{yt}$ & 258 & $\begin{array}{l}\text { 10-yr IBTR:APBI 6\% } \\
\text { vs 5\% WB( }(P=50)\end{array}$ & & $\begin{array}{l}\text { Excellent-good cosmesis: } \\
81 \% \text { APBl vs } 63 \% \text { WB }(P=009)\end{array}$ \\
\hline TARGITAI & $\begin{array}{l}\text { Multi- } \\
\text { country }\end{array}$ & $\begin{array}{l}245 y \mathrm{ys}, \mathrm{DC} \text {, } \\
\mathrm{T} 1 \text { and small } \\
\mathrm{T} 2, \mathrm{NO} / \mathrm{l} \text {, uni } \\
\text { focal, no EC, } \\
\text { CNO }\end{array}$ & $\begin{array}{l}\text { Widelocal } \\
\text { excision }\end{array}$ & $\begin{array}{l}40-56 \mathrm{~Gy} \\
\pm 10-16-\mathrm{Gy} \\
\text { boost }\end{array}$ & $\begin{array}{l}50 \mathrm{~W} x \text {-rays:5-7 Gy } \\
\text { at } 1 \mathrm{~cm} / 1 \mathrm{tx}\end{array}$ & $\begin{array}{l}\text { Not } \\
\text { reported }\end{array}$ & 2,232 & $\begin{array}{l}4 y I \text { IBTR } 1 \% \text { APBd } \\
\text { vs } 1 \% \text { WBI }(P=41)\end{array}$ & $\begin{array}{l}\text { If final path review showed ILC, } \\
\text { QC, or adverse criterion per local } \\
\text { center, then WBi added to APBI }\end{array}$ & 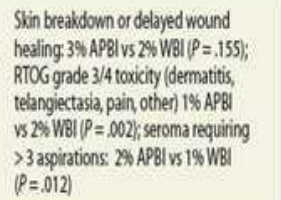 \\
\hline Elort. & italy & $\begin{array}{l}>45 \mathrm{yrs} \text {, tumor } \\
<2.5 \mathrm{~cm}\end{array}$ & $\begin{array}{l}\text { Quadrantectomy } \\
\text { and ALND or } \\
\text { SLNB }\end{array}$ & $\begin{array}{l}50 G y / 25 f x \\
+10-6 y b o o s t\end{array}$ & $\begin{array}{l}\text { Intraoperative } \\
\text { electrons:21Gy } \\
\text { to } 90 \% \text { IDUI fx }\end{array}$ & $\begin{array}{l}\text { Not } \\
\text { reported }\end{array}$ & 1,305 & 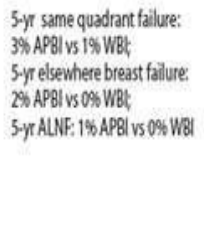 & $\begin{array}{l}\text { ASTROCS-acceptable pts: } \\
\text { 5-yr LRonly } 1.5 \%\end{array}$ & 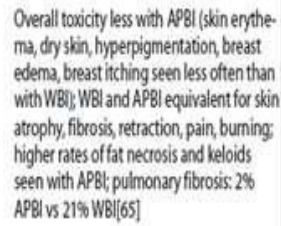 \\
\hline RAPDOF & Canada & $\begin{array}{l}240 \text { yrs, DCOS } \\
\text { or invasive } \\
\text { carcinoma f } \\
\text { tumors } 33 \mathrm{~cm} \text {, } \\
\text { pNO }\end{array}$ & $\begin{array}{l}\text { BCS with negative } \\
\text { margins, negative } \\
\text { ALND } \propto \text { SLNB }\end{array}$ & $\begin{array}{l}42.5 \mathrm{~Gy} / 16 \mathrm{fx} \text { or } \\
50 \mathrm{G} / 25 \mathrm{tx} \\
\text { (fillarge breast size) } \\
\pm 10-\mathrm{Gy} \text { tumor } \\
\text { bed boost }\end{array}$ & $\begin{array}{l}\text { 3D-CRT } 38.5 \\
\text { Gy/10txbid }\end{array}$ & $\begin{array}{l}\text { Not } \\
\text { reported }\end{array}$ & 2,135 & Pending & & 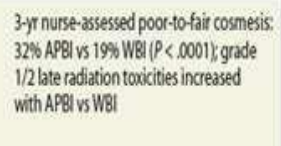 \\
\hline 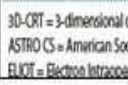 & 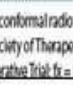 & 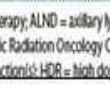 & 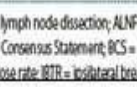 & 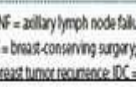 & 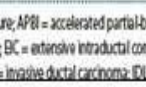 & 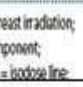 & \multicolumn{4}{|c|}{ 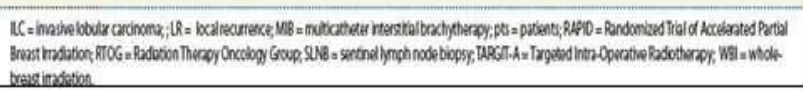 } \\
\hline
\end{tabular}


We are still awaiting the publication of the results from at least eight randomized controlled trials comparing WBI and APBI are ongoing (Table 5).

Table 5:- Randomized Phase III Clinical Trials Comparing ABBI and WBI are still ongoing.

\begin{tabular}{|c|c|c|c|c|c|c|c|c|c|}
\hline Tollone & Iaction & $\begin{array}{l}\text { Pater } \\
\text { indston Citara }\end{array}$ & Serpery & at & $\operatorname{Te} h=k \mathrm{NS}$ & $\begin{array}{l}\text { Datopened } \\
\text { Alsed }\end{array}$ & $\begin{array}{l}\text { Trase } \\
\text { Alene }\end{array}$ & Pinsen & Secontryifitpoies \\
\hline \multirow[t]{2}{*}{$\begin{array}{l}\text { searasa } \\
\text { 2006ses }\end{array}$} & \multirow[t]{2}{*}{ Sonter } & \multirow{2}{*}{ 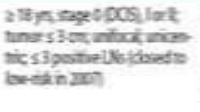 } & \multirow{2}{*}{ 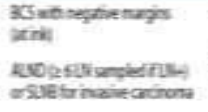 } & \multirow{2}{*}{ 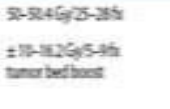 } & \multirow{2}{*}{ 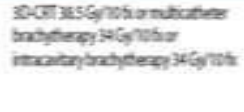 } & \multirow[t]{2}{*}{ काष } & \multirow[t]{2}{*}{4300} & \multirow[t]{2}{*}{ घE: } & \multirow{2}{*}{ 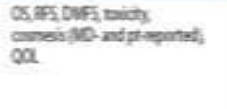 } \\
\hline & & & & & & & & & \\
\hline \multirow{2}{*}{ ipcer } & \multirow{2}{*}{ inted } & \multirow{2}{*}{ 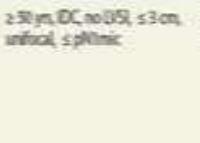 } & \multirow{2}{*}{ 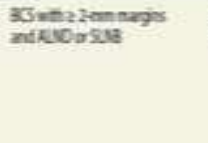 } & \multirow{2}{*}{$\begin{array}{l}\text { Av6yistruatcle } \\
\text { traer }\end{array}$} & ank ecgistrotunabet & \multirow[t]{2}{*}{ 2006200 } & \multirow[t]{2}{*}{$2 x$} & \multirow[t]{2}{*}{ ET: } & \multirow{2}{*}{ 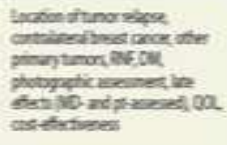 } \\
\hline & & & & & 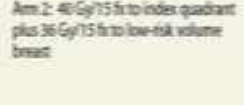 & & & & \\
\hline cheste & Earse & 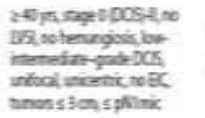 & 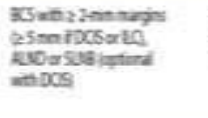 & 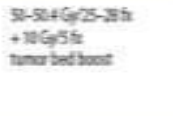 & 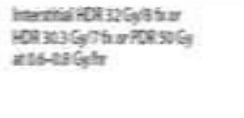 & Deszon & $\operatorname{in}$ & Bस & 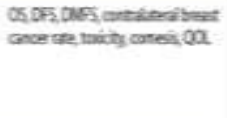 \\
\hline Bes & th & 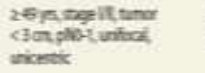 & $\begin{array}{l}\text { 35neizmnoris } \\
\text { nesterzo }\end{array}$ & 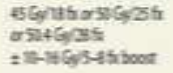 & Doureassenotibed & 20 & 130 & gin & 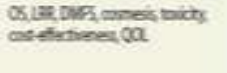 \\
\hline 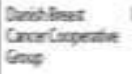 & Denst & 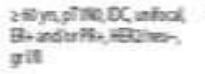 & 30 & esgest & ebyist & Is & $a$ & Ponse & 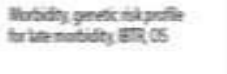 \\
\hline Sale & Reor & 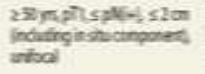 & 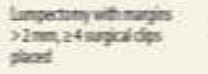 & 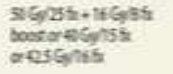 & 30- & zाI & 296 & हा? & 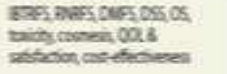 \\
\hline Henstif & tat & 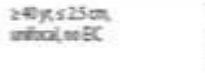 & 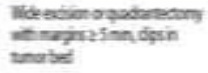 & sugsth & aersatstat & בxs & $\$$ & & \\
\hline \multicolumn{5}{|c|}{ 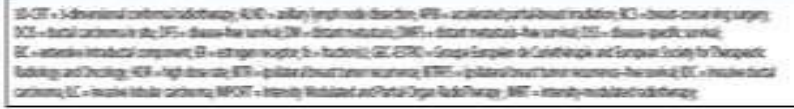 } & \multicolumn{5}{|c|}{ 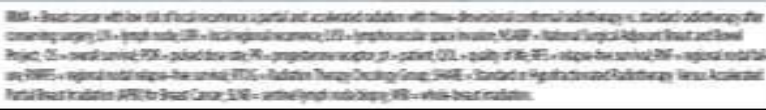 } \\
\hline
\end{tabular}

These trials [100-107] are being conducted in North America and Europe and in total will include over 16,000 women. The largest of these, the NSABP B-39/RTOG 0413 trial, is being conducted in the United States, with trial closure anticipated shortly. This trial will include 4,300 women with early-stage breast cancer randomly assigned to receive either WBI (with or without a tumor bed boost) or APBI. In this study, APBI can be delivered via MIB, single-entry brachytherapy catheter, or 3-dimensional conformal external beam radiation. While the trials are still open however they vary in terms of patient inclusion criteria and how APBI is delivered, we expect that they will provide definitive information on the equivalency of APBI to WBI. However, given the differences in the mode of APBI delivery in these studies, the findings of one may not be applicable to the technique used in another, in terms of either tumor control or toxicity. Meanwhile, investigators are attempting to answer such questions as whether MRI can be used to better define patients who can be treated with APBI, whether brachytherapy based APBI can be delivered with fewer total fractions, whether APBI can be delivered pre-operatively, and whether pathologic and surgical margin findings can be used for patient-specific target definition in APBI [108.109.110]. All these valid questions still need a clear answer hopefully by the ongoing phase III randomized clinical trials.

\section{Conclusion:-}

APBI is becoming an increasingly popular alternative to conventional WBI among women with early-stage breast cancer who desire breast conservation. It is a new technology that demonstrated long-term effectiveness and safety as compared to that of WBI for selected patients with early breast cancer. It is more convenient and is associated with better quality of life. However we believe that each patient should be considered as a special clinical case. The selection of optimum technique should be based on various factors relative to the tumor including (histopathology, stage, size, site) and the patient as age, comorbidities, social life, personal choice ,ec.). APBI must be individualized for every single patient. EBRT is an acceptable technique for APBI as it has more advantages than disadvantage and is established for a long period of time. At the end, more randomized clinical trials are still needed to reach a clear conclusion regarding the decision of the optimal role of APBI for the treatment of patient with early breast cancer. 


\section{Acknowledgment:-}

The authors acknowledge the support \& cooperation that was extended by Mr. Osama Mukhtar (Biostatistician) and Ms. Venus Ramilo (Medical Secretary) for preparing the manuscript and putting it in its final form.

\section{References:-}

1. Fisher B, Anderson S, Bryant J, et al. Twenty-year follow-up of a randomized trial comparing total mastectomy, lumpectomy, and lumpectomy plus irradiation for the treatment of invasive breast cancer. N Engl J Med. 2002;347:1233-41.

2. Darby S, McGale P, Correa $\mathrm{C}$, et al. Effect of radiotherapy after breast-conserving surgery on 10-year recurrence and 15-year breast cancer death: meta-analysis of individual patient data for 10,801 women in 17 randomised trials. Lancet. 2011;378:1707-16.

3. Veronesi U, Marubini E, Mariani L, et al. Radiotherapy after breast-conserving surgery in small breast carcinoma: long-term results of a randomized trial. Ann Oncol. 2001;12:997-1003.

4. Liljegren G, Holmberg L, Bergh J, et al. 10-Year results after sector resection with or without postoperative radiotherapy for stage I breast cancer: a randomized trial. J Clin Oncol. 1999;17:2326-33.

5. Mukesh M, Harris E, Jena R, et al. Relationship between irradiated breast volume and late normal tissue complications: a systematic review. Radiother Oncol. 2012;104:1-10.

6. Kuerer HM, Julian TB, Strom EA, Lyerly HK: Accelerated partial breast irradiation after conservative surgery for breast cancer. Ann Surg. 2004, 239: 338-351

7. Swanson TA, Vicini FA: Overview of accelerated partial breast irradiation. Curr Oncol Rep.2008, 10: 54-60.

8. Dragun AE, Harper JL, Taylor CE: Patient satisfaction and quality of life after MammoSite breast brachytherapy. Am J Surg. 2008, 196: 545-54

9. Sher DJ, Wittenberg E, Suh WW: Partial-breast irradiation versus whole-breast irradiation for early-stage breast cancer: a cost-effectiveness analysis. Int J Radiat Oncol Biol Phys. 2009, 74: 440-446.

10. Kawase E, Karasawa K, Shimotsu S, et al. Estimation of anxiety and depression in patients with early stage breast cancer before and after radiation therapy. Breast Cancer. 2012;19:147-52.

11. Whelan TJ, Levine M, Julian J, et al. The effects of radiation therapy on quality of life of women with breast carcinoma: results of a randomized trial. Ontario Clinical Oncology Group. Cancer. 2000;88:2260-6.

12. Lazovich DA, White E, Thomas DB, Moe RE. Underutilization of breast-conserving surgery and radiation therapy among women with stage I or II breast cancer. JAMA. 1991;266:3433-8.

13. Farrow DC, Hunt WC, Samet JM. Geographic variation in the treatment of localized breast cancer. N Engl J Med. 1992;326:1097-101.

14. Athas WF, Adams-Cameron M, Hunt WC, et al. Travel distance to radiation therapy and receipt of radiotherapy following breast-conserving surgery. J Natl Cancer Inst. 2000;92:269-71.

15. Ma AM, Barone J, Wallis AE, et al. Noncompliance with adjuvant radiation, chemotherapy, or hormonal therapy in breast cancer patients. Am J Surg. 2008;196:500-4.

16. McCarthy EP, Ngo LH, Roetzheim RG, et al. Disparities in breast cancer treatment and survival for women with disabilities. Ann Intern Med. 2006;145:637-45.

17. Mary Ella Sanders, Troy Scroggins: accelerated Partial Breast Irradiation in Early-Stage Breast Cancer. Journal of Clinical Oncology, Vol 25, No 8 (March 10), 2007: pp. 996-1002

18. Kahan Z, Csenki M, Varga Z: The risk of early and late lung sequelae after conformal radiotherapy in breast cancer patients. Int J Radiat Oncol Biol Phys. 2007, 68: 673-681.

19. Faverly DR, Burgers L, Bult P, Holland R: Three dimensional imaging of mammary ductal carcinoma in situ: clinical implications. Semin Diagn Pathol. 1994, 11: 193-198.

20. Imamura H, Haga S, Shimizu T: Relationship between the morphological and biological characteristics of intraductal components accompanying invasive ductal breast carcinoma and patient age. Breast Cancer Res Treat. 2000, 62: 177-184.

21. Veronesi U, Cascinelli N, Mariani L: Twenty-year follow-up of a randomized study comparing breastconserving surgery with radical mastectomy for early breast cancer. N Engl J Med.2002;347:1227-32

22. Holland R, Veling SH, Mravunac M: Histologic multifocality of Tis, T1-2 breast carcinomas. Implications for clinical trials of breast-conserving surgery. Cancer. 1985, 56: 979-990.

23. MXiu-peng Ye, Shen Bao:Accelerated Partial Breast Irradiation for Breast Cancer: A meta analysis. Oncology(2013) 6: 619-627

24. Goyal S, Kearney T, Haffty BG: Current application and research directions for partial-breast irradiation. Oncology (Williston Park). 2007, 21: 449-461. 
25. Sanders ME, Scroggins T: Accelerated partial breast irradiation in early-stage breast cancer. J Clin Oncol. 2007, 25: 996-1002.

26. Wadasadawala T, Budrukkar A: Quality of life after accelerated partial breast irradiation in early breast cancer: matched pair analysis with protracted whole breast radiotherapy.Clin Oncol(R Coll Radiol).2009,21:668-675

27. Darby SC, McGale P, Taylor CW, Peto R: Long-term mortality from heart disease and lung cancer after radiotherapy for early breast cancer: prospective cohort study of about 300,000 women in US SEER cancer registries. Lancet Oncol. 2005, 6: 557-565.

28. Schaapveld M, Visser O: Risk of new primary nonbreast cancers after breast cancer treatment: a Dutch population-based study.J Clin Oncol.2008,26:1239-1246.

29. Schaapveld M, Visser O: The impact of adjuvant therapy on contralateral breast cancer risk and the prognostic significance of contralateral breast cancer: a population based study in the Netherlands. Breast Cancer Res Treat. 2008, 110: 189-197.

30. Arthur DW, Vicini FA: Accelerated partial breast irradiation as a part of breast conservation therapy. J Clin Oncol. 2005, 23: 1726-1735.

31. Offersen BV, Overgaard M, Kroman N, Overgaard J: Accelerated partial breast irradiation as part of breast conserving therapy of early breast carcinoma: a systematic review. Radiother Oncol. 2009, 90: 1-13.

32. Zwicker RD, Arthur DW, Kavanagh BD, Mohan R, Schmidt-Ullrich RK: Optimization of planar high-dose-rate implants. Int J Radiat Oncol Biol Phys. 1999, 44: 1171-1177.

33. Zwicker RD, Schmidt-Ullrich R: Dose uniformity in a planar interstitial implant system. Int J Radiat Oncol Biol Phys. 1995, 31: 149-155.

34. Kuske RR: Breast brachytherapy. Hematol Oncol Clin North Am. 1999, 13: 543-558.

35. White JR, Winter KA, Kuske RR, et al. Long-term outcome from RTOG 95-17: a phase I/II study of accelerated partial breast irradiation (APBI) with multicatheter brachytherapy (MCT) following lumpectomy for early-stage breast cancer. J Clin Oncol. 2012;30(Suppl 27):Abstr 147.

36. Polgar C, Major T, Fodor J, et al, eds. Breast-conserving therapy with partial or whole breast RT: 10-year results of the Budapest randomized trial. World Congress of Brachytherapy; 2012; Barcelona, Spain.

37. Arthur DW, Vicini FA, Todor DA, et al. Improvements in critical dosimetric endpoints using the Contura multilumen balloon breast brachytherapy catheter to deliver accelerated partial breast irradiation: preliminary dosimetric findings of a phase IV trial. Int J Radiat Oncol Biol Phys. 2011;79:26-33.

38. Smith GL, Xu Y, Buchholz TA, et al. Brachytherapy for accelerated partial-breast irradiation: a rapidly emerging technology in breast cancer care. J Clin Oncol. 2011;29:157-65.

39. Niehoff P, Polgar C: Clinical experience with the MammoSite radiation therapy system for brachytherapy of breast cancer: results from an international phase II trial. Radiother Oncol. 2006, 79: 316-320.

40. Dragun AE, Harper JL: Predictors of cosmetic outcome following MammoSite breast brachytherapy: a singleinstitution experience of 100 patients with two years of follow-up. Int J Radiat Oncol Biol Phys. 2007, 68: 354358.

41. Vicini F, Beitsch PD: Three-year analysis of treatment efficacy, cosmesis, and toxicity by the American Society of Breast Surgeons MammoSite Breast Brachytherapy Registry Trial in patients treated with accelerated partial breast irradiation (APBI). Cancer. 2008, 112: 758-766.

42. Benitez PR, Keisch ME et al: Five-year results: the initial clinical trial of MammoSite balloon brachytherapy for partial breast irradiation in early-stage breast cancer. Am J Surg. 2007, 194: 456-462.

43. Dickler A, Patel RR, Wazer D: Breast brachytherapy devices. Expert Rev Med Devices. 2009, 6: 325-333.

44. Scanderbeg DJ, Yashar C : Evaluation of Three APBI Techniques Under NSABP B-39 Guidelines. J Appl Clin Med Phys. 2010, 11: 3021

45. Scanderbeg DJ, Yashar C, Rice R, Pawlicki T: Clinical implementation of a new HDR brachytherapy device for partial breast irradiation.Radiother Oncol.2009, 90: 36-42

46. Vicini F, Beitsch P, Quiet C, et al. Five-year analysis of treatment efficacy and cosmesis by the American Society of Breast Surgeons MammoSite Breast Brachytherapy Registry Trial in patients treated with accelerated partial breast irradiation. Int J Radiat Oncol Biol Phys. 2011;79:808-17.

47. Khan AJ, Arthur D, Vicini F, et al. Six-year analysis of treatment-related toxicities in patients treated with accelerated partial breast irradiation on the American Society of Breast Surgeons MammoSite Breast Brachytherapy registry trial. Ann Surg Oncol. 2012;19:1477-83.

48. Smith GL, Xu Y, Buchholz TA, et al. Association between treatment with brachytherapy vs whole-breast irradiation and subsequent mastectomy, complications, and survival among older women with invasive breast cancer. JAMA. 2012;307:1827-37. 
49. Presley CJ, Soulos PR, Herrin J, et al. Patterns of use and short-term complications of breast brachytherapy in the national Medicare population from 2008-2009. J Clin Oncol. 2012;30:4302-7.

50. Abbott AM, Habermann EB, Tuttle TM. Trends in the use of implantable accelerated partial breast irradiation therapy for early stage breast cancer in the United States. Cancer. 2011;117:3305-10.

51. Baglan KL, Sharpe MB, Jaffray D, et al. Accelerated partial breast irradiation using 3D conformal radiation therapy (3D-CRT). Int J Radiat Oncol Biol Phys. 2003;55:302-11.

52. Kozak KR, Doppke KP, Katz A, Taghian AG: Dosimetric comparison of two different three-dimensional conformal external beam accelerated partial breast irradiation techniques. Int J Radiat Oncol Biol Phys. 2006, 65: 340-346.

53. Vicini F, Winter K, Wong J: Initial Efficacy Results of RTOG 0319: Three-Dimensional Conformal Radiation Therapy (3D-CRT) Confined to the Region of the Lumpectomy Cavity for Stage I/II Breast Carcinoma. Int J Radiat Oncol Biol Phys. 2010, 77: 1120-1127

54. Vicini FA, Chen $P$ et al: Interim cosmetic results and toxicity using 3D conformal external beam radiotherapy to deliver accelerated partial breast irradiation in patients with early-stage breast cancer treated with breastconserving therapy. Int J Radiat Oncol Biol Phys. 2007, 69: 1124-1130.

55. Chen PY, Wallace M : Four-year efficacy, cosmesis, and toxicity using three-dimensional conformal external beam radiation therapy to deliver accelerated partial breast irradiation. Int J Radiat Oncol Biol Phys. 2010, 76: 991-997.

56. Taghian AG, El-Din MA: Interim results of a phase I/II trial of 3D-conformal external beam accelerated partial breast irradiation in patients with early breast cancer.Int J Radiat Oncol Biol Phys. 2008,72:S4-S4.

57. Hepel JT, Tokita M: Toxicity of three-dimensional conformal radiotherapy for accelerated partial breast irradiation. Int J Radiat Oncol Biol Phys. 2009, 75: 1290-1296.

58. Formenti SC, Rosenstein B: T1 stage breast cancer: adjuvant hypofractionated conformal radiation therapy to tumor bed in selected postmenopausal breast cancer patients-pilot feasibility study. Radiology. 2002, 222: 171178.

59. Bush DA, Do S, Lum S, Garberoglio C: Partial breast radiation therapy with proton beam: 5-year results with cosmetic outcomes. Int J Radiat Oncol Biol Phys. 2014;90:501-5

60. Vicini F, Winter K, Wong J, et al. Initial efficacy results of RTOG 0319: three-dimensional conformal radiation therapy (3D-CRT) confined to the region of the lumpectomy cavity for stage I/ II breast carcinoma. Int J Radiat Oncol Biol Phys. 2010;77:1120-7.

61. Whelan TJ, Olivotto I, Parpia S, et al. Interim toxicity results from RAPID: a randomized trial of accelerated partial breast irradiation (APBI) using 3D conformal external beam radiation therapy (3D CRT). Int J Radiat Oncol Biol Phys. 2013;85:21-22.

62. Taghian AG, Kozak KR, Katz A, et al. Accelerated partial breast irradiation using proton beams: Initial dosimetric experience. Int J Radiat Oncol Biol Phys. 2006;65:1404-10.

63. Kozak KR, Smith BL, Adams J, et al. Accelerated partial-breast irradiation using proton beams: initial clinical experience. Int J Radiat Oncol Biol Phys. 2006;66:691-8.

64. Bush DA, Slater JD, Garberoglio C, et al. Partial breast irradiation delivered with proton beam: results of a phase II trial. Clin Breast Cancer. 2011;11:241-5.

65. Vaidya JS, Joseph DJ, Tobias JS, et al. Targeted intraoperative radiotherapy versus whole breast radiotherapy for breast cancer (TARGIT-A trial): an international, prospective, randomised, non-inferiority phase 3 trial. Lancet. 2010;376:91-102.

66. Orecchia R. ELIOT Trials in Milan: Results. World Congress of Brachytherapy; Barcelona, Spain. 2012.

67. Khan AJ, Dale RG, Arthur DW, et al. Ultrashort courses of adjuvant breast radiotherapy: wave of the future or a fool's errand? Cancer. 2012;118:1962-70.

68. Holmes DR, Baum M, Joseph D: The TARGIT trial: targeted intraoperative radiation therapy versus conventional postoperative whole-breast radiotherapy after breast-conserving surgery for the management of early-stage invasive breast cancer (a trial update). Am J Surg. 2007, 194: 507-510

69. Vaidya JS, Tobias JS, et al: Intraoperative radiotherapy for breast cancer. Lancet Oncol. 2004, 5: 165-173.

70. Kraus-Tiefenbacher U, Scheda A: Intraoperative radiotherapy (IORT) for breast cancer using the Intrabeam system. Tumori. 2005, 91: 339-345.

71. Orecchia R, Luini A: Electron intraoperative treatment in patients with early-stage breast cancer: data update. Expert Rev Anticancer Ther. 2006, 6: 605-611.

72. Mussari S, Sabino Della Sala W: Full-dose intraoperative radiotherapy with electrons in breast cancer. First report on late toxicity and cosmetic results from a single-institution experience. Strahlenther Onkol. 2006, 182: 589-595. 
73. Karni T, Pappo I, Sandbank J: A device for real-time, intraoperative margin assessment in breast-conservation surgery. Am J Surg. 2007, 194: 467-473.

74. Vaidya JS, Tobias JS, Baum M, et al. Intraoperative radiotherapy for breast cancer. Lancet Oncol. 2004;5:16573.

75. Bartelink H, Horiot JC, Poortmans PM, et al. Impact of a higher radiation dose on local control and survival in breast-conserving therapy of early breast cancer: 10-year results of the randomized boost versus no boost EORTC 22881-10882 trial. J Clin Oncol. 2007; 25:3259-65.

76. Rosenstein BS, Lymberis SC, Formenti SC. Biologic comparison of partial breast irradiation protocols. Int J Radiat Oncol Biol Phys. 2004;60:1393-404.

77. Bentzen SM, Yarnold JR. Reports of unexpected late side effects of accelerated partial breast irradiationradiobiological considerations. Int J Radiat Oncol Biol Phys. 2010;77:969-73.

78. Faverly DR, Hendriks JH, Holland R. Breast carcinomas of limited extent: frequency, radiologic-pathologic characteristics, and surgical margin requirements. Cancer. 2001;91:647-59.

79. Nguyen BT, Deb S, Fox S, et al. A prospective pathologic study to define the clinical target volume for partial breast radiation therapy in women with early breast cancer. Int J Radiat Oncol Biol Phys. 2012;84:1116-22.

80. Cuttino LW, Todor D, Pacyna L, et al. Three-dimensional conformal external beam radiotherapy (3D-CRT) for accelerated partial breast irradiation (APBI): what is the correct prescription dose? Am J Clin Oncol. 2006;29:474-8.

81. Chen PY, Vicini FA, Benitez P, et al. Long-term cosmetic results and toxicity after accelerated partial-breast irradiation: a method of radiation delivery by interstitial brachytherapy for the treatment of early-stage breast carcinoma. Cancer. 2006;106:991-9.

82. Polgar C, Sulyok Z, Fodor J, et al. Sole brachytherapy of the tumor bed after conservative surgery for T1 breast cancer: five-year results of a phase I-II study and initial findings of a randomized phase III trial. J Surg Oncol. 2002;80:121-8; discussion 29.

83. Wazer DE, Lowther D, Boyle T, et al. Clinically evident fat necrosis in women treated with high-dose-rate brachytherapy alone for early-stage breast cancer.Int J Radiat Oncol Biol Phys.2001;50:107-11.

84. Albuquerque K, Tell D, Lobo $\mathrm{P}$, et al. Impact of partial versus whole breast radiation therapy on fatigue, perceived stress, quality of life and natural killer cell activity in women with breast cancer. BMC Cancer. 2012;12:251.

85. Hattangadi J, Taback N, Neville BA, et al. Accelerated partial breast irradiation using brachytherapy for breast cancer: patterns in utilization and guideline concordance.J Natl Cancer Inst.2012;104:1-13

86. Suh WW, Pierce LJ, Vicini FA, Hayman JA. A cost comparison analysis of partial versus whole-breast irradiation after breast-conserving surgery for early-stage breast cancer. Int $\mathrm{J}$ Radiat Oncol Biol Phys. 2005;62:790-6.

87. Sher DJ, Wittenberg E, Suh WW, et al. Partial-breast irradiation versus whole-breast irradiation for early-stage breast cancer: a cost-effectiveness analysis. Int J Radiat Oncol Biol Phys. 2009;74:440-6.

88. Shah C, Lanni TB, Saini H, et al. Cost-efficacy of acceleration partial-breast irradiation compared with wholebreast irradiation. Breast Cancer Res Treat. 2013;138:127-35.

89. Lanni T, Keisch M, Shah C, et al. A cost comparison analysis of adjuvant radiation therapy techniques after breast-conserving surgery. Breast J. 2013;19:162-7.

90. Smith BD, Arthur DW, Buchholz TA, et al. Accelerated partial breast irradiation consensus statement from the American Society for Radiation Oncology (ASTRO). Int J Radiat Oncol Biol Phys. 2009;74:987-1001.

91. Polgar C, Van Limbergen E, Potter R, et al. Patient selection for accelerated partial-breast irradiation (APBI) after breast-conserving surgery: recommendations of the Groupe Europeen de Curietherapie-European Society for Therapeutic Radiology and Oncology (GEC-ESTRO) breast cancer working group based on clinical evidence (2009). Radiother Oncol. 94:264-73.

92. Board of Directors ASoBS. Consenus statement for accelerated partial breast irradiation. 2011. Accessed March 26, 2013.

93. Breast Brachytherapy Task Group, ABS. ABS Breast Brachytherapy Task Group. 2007. Accessed March 26, 2013.

94. NCCN (National Comprehensive Cancer Network) Guidelines of Breast Cancer (2015).

95. AIRO associazione:la radioterapia dei tumori della Mammella Indicazione e Criteria Guida 2013.

96. Smith BD, Arthur DW,et al: Accelerated partial breast irradiation consensus statement from the American Society for Radiation Oncology(ASTRO).Int J Radiat Oncolo Biol Phys.2009,74:987-1001

97. Polgar C, Van Limbergen E, et al: Patient selection for accelerated partial-breast irradiation (APBI) after breastconserving surgery: recommendations of the Groupe Europeen de Curietherapie-European Society for 
Therapeutic Radiology and Oncology (GEC-ESTRO) breast cancer working group based on clinical evidence (2009). Radiother Oncol. 2010, 94: 264-273.

98. Vicini F, Arthur D, Wazer D, et al. Limitations of the American Society of Therapeutic Radiology and Oncology Consensus Panel guidelines on the use of accelerated partial breast irradiation. Int J Radiat Oncol Biol Phys. 2011;79:977-84.

99. Shaitelman SF, Vicini FA, Beitsch P, et al. Five-year outcome of patients classified using the American Society for Radiation Oncology consensus statement guidelines for the application of accelerated partial breast irradiation: an analysis of patients treated on the American Society of Breast Surgeons MammoSite Registry Trial. Cancer.2010;116:4677-85.

100. Wolmark N, Curran W. NSABP Protocol B-39. RTOG Protocol 0413. A randomized phase III study of conventional whole breast irradiation (WBI) versus partial breast irradiation (PBI) for women with stage 0 , I, or II breast cancer. 2011.

101. Coles C, Yarnold J. The IMPORT trials are launched (September 2006). Clin Oncol (R Coll Radiol). 2006;18:587-90.

102. Yarnold J. Randomised trial testing intensity modulated and partial organ radiotherapy after breast conservation surgery for early breast cancer. 2008 [updated January 6, 2011]. Available from: http://www.clinicaltrials.gov/ct2/show/NCT00814567. Accessed March 26, 2013.

103. Strnad V, Polgár, C. Interstitial brachytherapy alone versus external beam radiation therapy after breast conserving surgery for low risk invasive carcinoma and low risk duct carcinoma in-situ (DCIS) of the female breast.

104. Frezza G, Bertoni, F. IRMA. Breast cancer with low risk of local recurrence: partial and accelerated radiation with three-dimensional conformal radiotherapy (3DCRT) vs. standard radiotherapy after conserving surgery (phase III study). 2007.

105. Danish Breast Cancer Cooperative Group. Partial breast versus whole breast irradiation in elderly women operated on for early breast cancer. 2011.

106. Belkacemi Y, Lartigau, E. Standard or hypofractionated radiotherapy versus accelerated partial breast irradiation (APBI) for breast cancer (SHARE). 2011.

107. Livi L, Buonamici FB, Simontacchi G, et al. Accelerated partial breast irradiation with IMRT: new technical approach and interim analysis of acute toxicity in a phase III randomized clinical trial. Int J Radiat Oncol Biol Phys. 77:509-15.

108. Schmitz AC, Pengel KE, Loo CE, et al. Pre-treatment imaging and pathology characteristics of invasive breast cancers of limited extent: potential relevance for MRI-guided localized therapy. Radiother Oncol. 2012;104:118.

109. Palta M, Yoo S, Adamson JD, et al. Preoperative single fraction partial breast radiotherapy for early-stage breast cancer. Int J Radiat Oncol Biol Phys. 2012;82:37-42.

110. Dorn PL, Al-Hallaq HA, Haq F, et al. A prospective st6dy of the utility of magnetic resonance imaging in determining candidacy for partial breast irradiation.Int J Radiat Oncol Biol Phys.2013;85:615-22. 